\title{
Children's Voices in the Polish Canon Wars: Participatory Research in Action
}

Ewa Chawar, Justyna Deszcz-Tryhubczak, Katarzyna Kowalska, Olga Maniakowska, Mateusz Marecki, Milena Palczyńska, Eryk Pszczołowski, Dorota Sikora

\section{Summary}

Despite its rightful concern with childhood as an essentialist cultural construct, the field of children's literature studies has tended to accept the endemicity of asymmetrical power relations between children and adults. It is only recently, under the influence of children's rights discourses, that children's literature scholars have developed concepts reflecting their recognition of more egalitarian relationships between children and adults. This essay is a result of the collaboration between child and adult researchers and represents a scholarly practice based on an intergenerational democratic dialog in which children's voices are respected for their intrinsic salience. The presence of child researchers in children's literature studies confirms an important shift currently taking place in our field, providing evidence for the impossibility of regarding children's literature only as a manifestation of adult power over young generations.

Key words: School canon, childism, children's voices, participatory research, intergenerational dialogue

(Justyna and Mateusz)

The aim of our contribution is purposely confrontational: it is directed against the adultism prevailing in children's literature studies. The adult-dominated nature of our field limits children's voices to reader-response research, which usually objectifies young readers. We propose that a new frontier of our field lies in repositioning currently popular theories and approaches to children's texts within a child-centred framework that overtly reflects our acknowledgment of young readers as subjects and agents of change who have the right to coconstruct the political, economic and socio-cultural realities they share with adults. While we do not claim that this approach is better, or worse, than any other methodology, we seek to 
show that, as children's literature scholars, one way we can contribute to children's participation is by facilitating their access to academic spaces and by developing projects in which child researchers shape the procedures and engage in the co-production of knowledge and critical reflection related to the texts they read. We claim that the use of this method as an alternative to traditional adult-dominated research can be especially fruitful in our field to promote intergenerational connections. After all, children's literature itself represents, embodies and enables a cultural, socioeconomic and political network of bonds, interactions, allegiances and commitments among children and adults.

We exemplify our approach by outlining the findings of 'Deconstructing the Canon with Elementary School Students: Participatory Research in Practice', a project we have been conducting in partnership with children since 2016 to address recent changes in the primary literature curriculum in Poland. The selection of national and foreign literary works, including children's books, to be taught at Polish schools remains a central issue in public debate about the condition of the Polish education system. While this debate usually involves teachers, journalists, literary scholars and parents, it is rare for pupils' own preferences to be heard above the noise created by adult stakeholders in education. The project focuses on the possibility of children's active participation in decisions shaping the formation of school reading curricula and tests the feasibility of an intergenerational exchange space where such discussions could take place. We find it surprising that while scholars almost unanimously see literary canons as pluralist and ever evolving under the influence of, for example, Marxism, feminism, postmodernism or LGBTQ movements, there is no theoretical or practical discussion of how school reading lists could be influenced by the growth of children's protagonism. We argue that the formation of the school canon should enable the participation of child readers by proposing a model approach that could potentially be implemented in all 
school types, and especially in countries where school canons are developed within centralised educational systems.

A paper jointly authored by child and adult participants was presented at the 2017 IRSCL congress. For this Research in Action feature, the two sets of co-researchers again joined forces to provide a multi-perspectival discussion of the development of the project, emphasising metacritical inquiry into the dynamics, intensities and forms of the child- and adult-initiated activities it entailed. In the first section of this article, two of the adult researchers, Justyna and Mateusz, contextualise the canon wars in Poland in the current debates about children's literature and school. They then reflect on the rationale, potential and challenges of participatory research engaging children as co-researchers. The remainder of the article focus directly on the project, placing the young researchers at its centre and so recognising their ownership of the research as they present and discuss their findings. The essay concludes with all the participants' scrutiny of their involvement in the project and their remarks on the possible reverberations of our approach in children's literature scholarship and beyond it. As we are aware that this article is rightly likely to raise questions concerning the power differentials at work in our collaborative enterprise, we want to stress that the child authors provided feedback on the adult-authored sections and vice versa.

\section{A Childist School Canon?}

(Justyna and Mateusz)

For Pierre Bourdieu, institutions of education have the highest power of canonisation: 'It is impossible to understand the peculiar characteristics of restricted culture without appreciating its profound dependence on the educational system, the indispensable means of its reproduction and growth' (15). Education systems legitimate the canon by shaping both its consumers and future guardians. Yet now that children have a much wider range of 
knowledge and interactive social relations than in the past, school reading lists should be an arena where national policies and the content of curricula correspond to children's changing competences, interests, and needs. The surprising myopia concerning children's agency in relation to the canon marks the most recent publication on canonicity in children's literature, Canon Constitution and Canon Change in Children's Literature, edited by Bettina Kümmerling-Meibauer and Anja Müller. The editors point out that in light of the constructed nature of childhood and the impossibility of reflecting 'the universal child . . . in a canon, it is the less wonder that a canon of children's literature is subject to change' (6). Nonetheless, they fail to explain how the influence of the idealised models of childhood on the canon could be destabilised by a child-centred approach that would enable real children to shape it.

The same lack of constructive reflection on the potential of children's intervention in the canon-making processes is visible in Anna Maria Czernow and Dorota Michułka's contribution to that collection, 'Historical Twists and Turns in the Polish Canon of Children's Literature,' which is of particular interest to us as it outlines the development of policies concerning school reading in post-communist Poland. The authors point out consistent attempts at 'the de-ideologisation' of school literature curricula involving not only the inclusion of more contemporary texts appealing to pupils' interest, but also the decentring of the very process of creating reading lists through the incorporation of pupils' choices (94). They blame the failure to achieve this goal on teachers' conservative attitudes and the lack of clear guidelines in the curriculum itself (98), but this matter is far more complex. In fact, virtually no literature education specialists in Poland have reflected on how children's intervention in the school canon could actually be put into practice, which in turn could be seen as a lack of academic support for opening the pedagogical canon to children's preferences. $^{1}$ 


\section{Childist Revolution in Children's Literature Studies?}

(Justyna and Mateusz)

As indicated by the titles of the 2017 and 2019 IRSCL congresses ('Possible \& Impossible Childhoods: Intersections of Children's Literature \& Childhood Studies' and 'Silence and Silencing in Children's Literature', respectively), our field is becoming increasingly concerned with real child readers, both contemporary and from the past, as rightful commentators on cultural phenomena. This approach replaces the dominance of longstanding attitudes which construct child readers as not yet competent interpreters of literature who are gradually accruing diverse cognitive and emotional skills. ${ }^{2}$ Appreciating young readers' expertise necessitates developing a new methodology to enable the joint child-adult co-construction of culturally, socially, and politically contextualised knowledge about children's engagements with literature. We cannot help but think here of John Wall's proposition of a childist revolution in the humanities that would result in an unprecedented centrality of children in scholarship. As he argues,

[c]hildren will take a central place in humanities scholarship only if there is a revolution on a similar scale to the revolutions that have occurred in connection with other 'minorities'. Art, literature, history, culture, philosophy, religion, and the like would need to be considered narrow and stunted if they did not account for age in addition to gender, sexuality, class, race, and ethnicity. (689).

Wall distinguishes his use of the concept childism from 'childist' criticism for children's literature, in which adults are encouraged to read as children (Hunt 1984). He also acknowledges the concern that childism, similarly to such negative terms as racism and sexism, can be used to address 'antichild prejudice and oppression' (71). Yet Wall proposes to 
use childism 'to identify not only what victimizes children but also what empowers them' (71). Although the field of children's literature studies is undeniably childist in the positive sense proposed by Wall, we believe that it can embrace a more radical form of childism by paving the way towards child-inclusive humanistic methodologies. Such approaches could transform prevalent norms and strategies for reading literature and become a model of academic practice aimed at promoting intergenerational cohesion and counteracting antichild prejudice. As we show, one way this goal could be achieved is by engaging young readers as partners in research.

Since the 1970s, the notion of children as social actors with agency has been one of the core foundations of the 'new social studies of childhood' (James and Prout, 1990), developed to question the predominance of socialisation theory and developmental psychology as the framework of the study of childhood (Tisdall and Punch, 2012). The new paradigm has sought to challenge the understanding of childhood through the lens of what Nick Lee refers to as 'the cultural distinction between human being and human becoming' (19). While the former connotes self-determination, experience, knowledge, and, as a result, a higher social status, the latter means unawareness of social norms, lack of cultural competence (read: not knowing what is good for oneself), and the process of moral, intellectual and functional preparation for adulthood and full citizenship (19). The above distinction has led to silencing children as full members of society alongside sanctioning 'their use as a resource instead of their inclusion as citizens with views and preferences of their own' (4). To counteract this objectification, the new paradigm stresses the importance of children's worldviews, voices, and agency that emerge in the context of their everyday lives and experiences. More specifically, it emphasises children's ability to form their own opinions, make their own decisions about their own lives and act independently of adults (138). To be able to respond to these key imperatives and commitments, childhood research is 
now underpinned by the assumption that children should be studied in and for themselves. Research should emphasise the perspective of the children being researched, with adult scholars considering the diverse historical, social, and geographical circumstances of individual childhoods.

An especially important aspect of the new sociology of childhood has been the notion of children's independent agency and autonomy (Tisdall and Punch 251). Yet some scholars have begun to contest the emphasis on the individualist nature of children's agency and argued for 'relational agency and interdependency as concepts which better reflect how children (and indeed, adults) are socially embedded in the navigation of their worlds' (Richards et al. 36). In Ethical Research with Children: Narratives and Taboos, Richards et al. reflect on their own experiences in research with individual children as sources of knowledge about their lives. They conclude that children's co-construction of power relations in various social contexts, including research, involves not only 'the skills of autonomy', but also, and to a more substantial extent, the establishment and negotiation of social relations and connectivity. Putting children's dependence/autonomy into perspective, they rightly stress that both individualism and interdependence are in fact 'idealized cultural script[s]' that should best be combined into a relational model of autonomy which acknowledges children 'as active in reciprocal relationships rather than the abstract individual commonly found in the language of autonomy, rights and ethics' (87). Hence they propose developing research relationships which emphasise the situatedness and temporariness of the acquisition and exercise of children's agency as it occurs in response to specific social interactions. As we later show, this contingency substantially influenced the child participants' involvement in our project, making us acknowledge intergenerational power relationships shaping our realities.

With the above in mind, we fully support children's protagonism and its centrality in developing communities and society in general. We also agree with Priscilla Alderson, among 
others, that children are qualified to explore their social lives and culture not only as active participants but also as active researchers who "can "speak" in their own right and report valid views and experiences' (278). Moreover, child researchers can facilitate access to other children's views and experiences and the 'novelty and immediacy of children's research reports can attract greater publicity and interest in using the findings than much adult research does' (287). While participatory research with children as actively engaged in the research process is usually, and rightly, seen as a way to fulfil the postulates of the United Nations Convention on the Rights of the Child (UNCRC), it may also be perceived as an effective means of encouraging relational agency for children as adults. Such methodologies enable developing an awareness of specific social contexts and the interdependent agents involved in them and in the research process.

Granted, participatory methodologies pose serious problems. The most immediate concerns are undoubtedly the issues of power, the risk of burdening children with too much responsibility, and the thin line between adults' support for and control of their young collaborators. Other questions that frequently appear in relation to participatory research concern interventions of gatekeepers and their influence on power relations or the ownership of results and outputs. As Alderson emphasises, although cooperation with child researchers may in fact intensify asymmetries of power, the course of research needs to be decided upon with young researchers, of which '[o]ne advantage is that there is often more time to talk with child researchers than with child research subjects, and to turn problems into opportunities for children and adults to increase their skill and knowledge' (287). As we show later, such unexpected twists happened also in our project, prompting the intergenerational research team to find alternative ways to continue its cooperation and remain within the ethical boundaries of research with children. 
A challenge that is perhaps more difficult to overcome than the organisational and ethical complications that may arise in cooperation with child researchers is the partial loss of professional authority. As we share with them the knowledge of scholarly methods to build their capacities, we also risk losing the 'cherished conceits' in research such as 'objectivity and neutrality and the importance of a distanced researcher' (Richards et al 83). Moreover, participatory collaboration with children requires embracing the stance of 'methodological immaturity' (Gallacher and Gallagher 499), which entails approaching such ventures without predetermination but with openness to children's appropriation of ourselves and our research tools. The aim of participatory research with children is not 'to discover or uncover a preexisting world' (513), which is often the case in text-oriented literature studies, but a world and identities always in-the-making. It is this relationality and interdependence, combined with unpredictability, that children's literature scholars may find especially difficult not only to accept but to recognise as potentially a productive aspect of the research process. As we illustrate through our discussion of the importance of young readers' contribution to canon formation, intergenerational participatory research might prove to be a truly empowering experience benefiting all parties involved.

\section{Project Description}

(Justyna and Mateusz)

Prompted by the provocative possibility of a child-cantered school canon, we formed an intergenerational research team comprising a mixed-gender group of ten fifth and sixth graders (aged 11-13) $)^{3}$ working in close collaboration with three adults, to conduct a readerresponse study and to evaluate the potential of participatory research in the process. The young researchers involved in the project have much in common: they all live in urban environments, belong to the same discussion club (Educational Discussion Club at Primary 
School No. 28 in Wrocław), read voraciously across genres and voluntarily participate in various extracurricular activities promoting reading. Significantly, like their adult collaborators - their Polish language teacher (Ewa) and two children's literature scholars (Justyna and Mateusz), they expressed their dissatisfaction with the adult-centred debate about school canons which dismisses their voices as unworthy of consideration and, in effect, fails to account for their disparate needs, experiences, and literary tastes ${ }^{4}$. Our joint collaboration - to look critically at the process of designing reading curricula for Polish primary schools - arose partly out of that concern. It was driven by our shared need to encourage a democratic negotiation of reading lists between Polish teachers and their students. This quickly established common ground soon translated into a sense of kinship and mutual trust that facilitated our interactions. The project spanned sixteen months (March 2016 to July 2017) and involved three strategic meetings. Although our research encounters were all held in a classroom, an 'adult-controlled social setting' (Horgan 249) which could have impeded student engagement since it might have been seen as part of traditional school power relations, we strove to create an informal and egalitarian environment for discussion by reorganising the space into a circular desk arrangement.

The first two meetings began with adult-initiated opening remarks and then turned into free-flowing debates involving all participants. We devoted much space to planning, goalsetting and establishing methodological frames for our study. Having learnt from their adult collaborators about different forms of qualitative and quantitative research, the young researchers selected the survey, the focus group, and observation as their chief methods for enquiring into their peers' reading preferences with a view to establishing a new canon of books that would be more in line with primary school students' needs and expectations. At the conclusion of Meeting Two, they divided themselves into three groups, distributed project work evenly and agreed on the time, place and scope of the study. A few months later, when 
we met again to discuss the findings of their multi-angled research, the young researchers presented us with illuminating data and insights. Working as three independent groups, they elicited comments from 124 survey respondents of primary school age, organised a meeting of a focus group consisting of four female pupils from grade 4, and conducted the observation part of the study in the school corridors and library to find out how many of their peers read books during breaks. As a follow-up to this report, our research team engaged in a brainstorming session to ponder possible ways of disseminating the results to propagate a democratic intergenerational approach to the canon of school readings. We decided to issue a visually appealing leaflet (Fig. 1), designed by the young researchers and Ewa, and to send a letter to the Polish Ministry of National Education, written jointly and signed by the children and adults involved in the project. Both the leaflet and the letter met with positive reception on the part of the school community and policymakers. The appreciative feedback we received from the Ministry of National Education specified how our project could be advanced and expanded nationwide, for example by encouraging pupils to contribute to their school libraries' purchase orders.
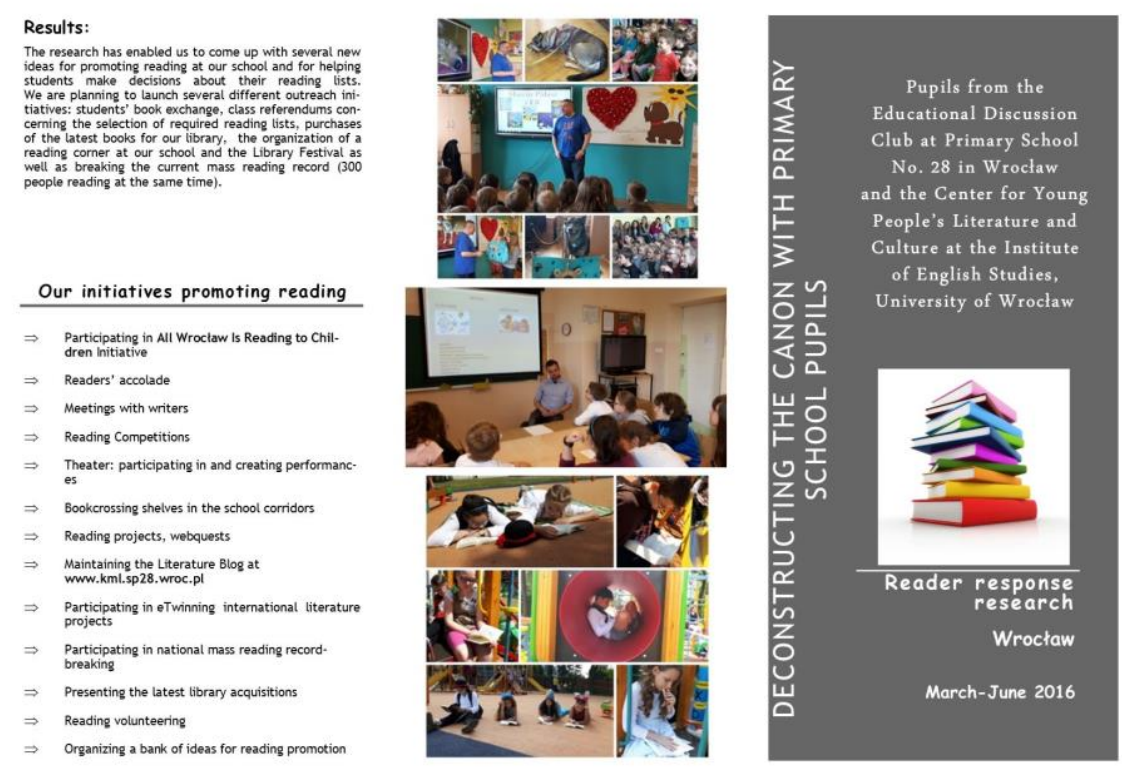

Fig. 1 The cover of the English version of project's brochure 


\section{From Supervised Participants to Primary Researchers}

(Justyna and Mateusz)

The account provided above offers only a fractional glimpse into the dynamics behind our project; it gives a slightly misleading impression about power and control shifts occurring between all participants involved. On the face of it, the account is biased in favour of the young researchers, reducing the adults' contribution to initiation and knowledge sharing. In reality, however, these intergenerational interactions were more fluid and diverse. While the adult researchers were seamlessly juggling the scripts of a fraternal 'least-adult' figure (Warming 39) and a supervising teacher, their young collaborators were switching smoothly between their roles as supervised participants relying on adult assistance and full-fledged primary researchers. With the aid of Tina Moules and Niahm O'Brien's dual-axis model (2011), it can be thus demonstrated that the degree of participation and decision-making achieved in the course of our collaboration fluctuated and varied at different stages of the project. By placing these two dimensions of our collaboration-decision-making and initiation/direction — on a three-phase continuum, as proposed by Moules and O'Brien, we were able to pinpoint those moments 'where decision making and initiation and direction lay with the adults, those occasions where the two dimensions lay mainly with the children, and those occasions where they were shared' (19).

Inevitably, both our induction meeting, which aimed to build team relationships and set out the conditions for our intergenerational undertaking, and the first half of Meeting Two, focused on Mateusz's presentation on data collection methods, were dominated by the adult participants. Soon after, however, the young researchers, equipped with new analytical tools and attracted by the prospect of a study touching upon their own lives, took over and engaged in a lively exchange of opinions. This stage marked the transition from 'adultist guidance' (Horgan 255) to child-controlled action in the form of a brainstorming session when power 
balance shifted perceptibly towards shared direction and decision-making. All participants were invited freely to partake in method selection, goal-setting and planning.

Despite our attempts to put everyone on an equal footing, the adult co-researchers, and especially Ewa as the trusted teacher and team mediator in one, would occasionally step out of their roles as fraternal figures to keep discussions within available time limits. Importantly, these interventions were never aimed at eliciting socially desirable responses from the young researchers. Still, issues concerning the difficulty of transcending the traditional confines of student-teacher relations would re-emerge as our project advanced. For instance, while putting the finishing touches to our letter to the Ministry of National Education, we were asked by the school's headteacher to tone down our message. Indicatively, adultist control, whether exercised in the form of parental consent, e-mail correspondence maintained exclusively between the adult participants or unsolicited help with English translation and PowerPoint presentations, met with no protest on the part of the child researchers. Clearly, this 'emphasis on consultation' (Horgan 247), coupled with the young participants' silent acceptance of adult supervision, is firmly grounded in certain expectations and responsibilities ascribed to adults in general and teachers in particular. Although our intergenerational collaboration failed to achieve ‘deep participation' (Kesby 2814), since our co-construction of knowledge was partly framed and driven by the school, we strove to keep inevitable power inequalities to a minimum by stressing child-adult interdependencies, adopting lesser adult roles and building in the young researchers capacity and a sense of responsibility for their own lifeworlds. Our attempts have been appreciated by our co-researchers.

(Kasia)

The adults participating in the project suggested some ideas, but if we did not like them, they were prepared to look for a compromise. In my opinion, the project is more the children's 
work than the adults'. We were limited only by the focus and had a lot of room for our own contribution.

(Milena)

I believe that the adults' contribution was adequate as they supervised us and corrected our mistakes. We could talk to them whenever we had any doubts. Justyna and Mateusz disseminated our results in Poland and in Toronto. Ms. Chawar did her best to support us at school.

(Eryk)

The adults' participation in the project was not too big. It was limited to channelling our ideas and adding some more. The adults followed a relaxed approach which both gave us a lot of freedom and prevented us from going off our course.

(Dorota)

Substantial work in the project was done by the pupils, who designed and conducted the surveys and analysed them. Some of the pupils also took part in a debate on the school readings. Of course, it could not have happened without the adults. If it had not been for the adult scholars and Ms. Chawar, whose help and support cannot be overestimated, the project would not have such a scope. It would not have been created at all. The co-ordination of the project is the adults' achievement.

(Justyna and Mateusz)

The child researchers made several attempts at redressing those power imbalances themselves by taking the lead in the critical phases of the project. On their own initiative, some of the older participants took responsibility for distributing work and dividing child collaborators into three research teams. Within their respective groups, all young researchers played active parts in formulating the goals of their research, selecting methods to achieve them and leading the tripartite study entirely on their own. At this stage of the project, control and power moved 
decidedly towards the child collaborators, who acted as primary researchers shaping the formation of school reading as an element of a particular social, cultural and economic context. While analysing and interpreting the collected data during Meeting Three, they shared their extensive expert knowledge (as evidenced below) with the adult participants. The striking element recurring in the majority of their comments is their surprise at some of the findings. We see this reaction as testifying to the potential of participatory projects like ours to provide insights into children's perceptions and experiences of the world around them. Finally, the young researchers proposed their ideas for the dissemination of the results, which testifies to their sense of ownership and their concern about the possible impact and reverberations of our concerted endeavour.

(Olga)

I am glad that pupils had some influence on the choice of the obligatory books because they were able to choose a topic that interests them and gets through to them. But I am not in favour of pupils choosing all the books (I am talking about the primary school level) because in that case they would totally reject classics, saying that they are 'boring'. Independent choices concerning school reading would work only for older pupils because they will have a greater awareness of what types of books to choose from so that they would enjoy them and find them appealing. 


\section{Does your class have any influence on the selection}

\section{of school readings?}

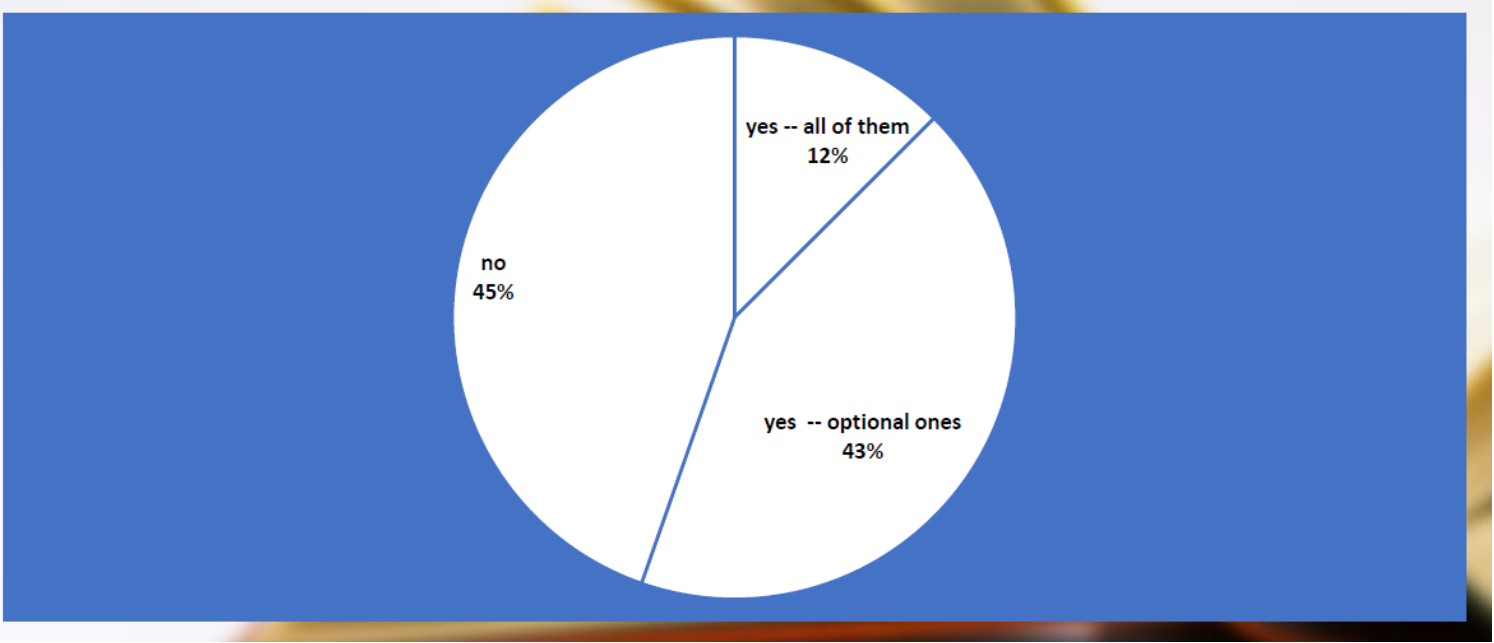

Fig. 2 The selection of school readings

\section{(Katarzyna)}

I was pleasantly surprised by the results of the 'What does reading mean to me?' questionnaire. You could choose between two answers: 'reading is an obligation to me' or 'reading is a pleasure to me'. I had thought that most of the respondents would answer that reading is an obligation to them. But decidedly more of them said that for them reading is enjoyable. Apparently, pupils like books and know that reading has many benefits.

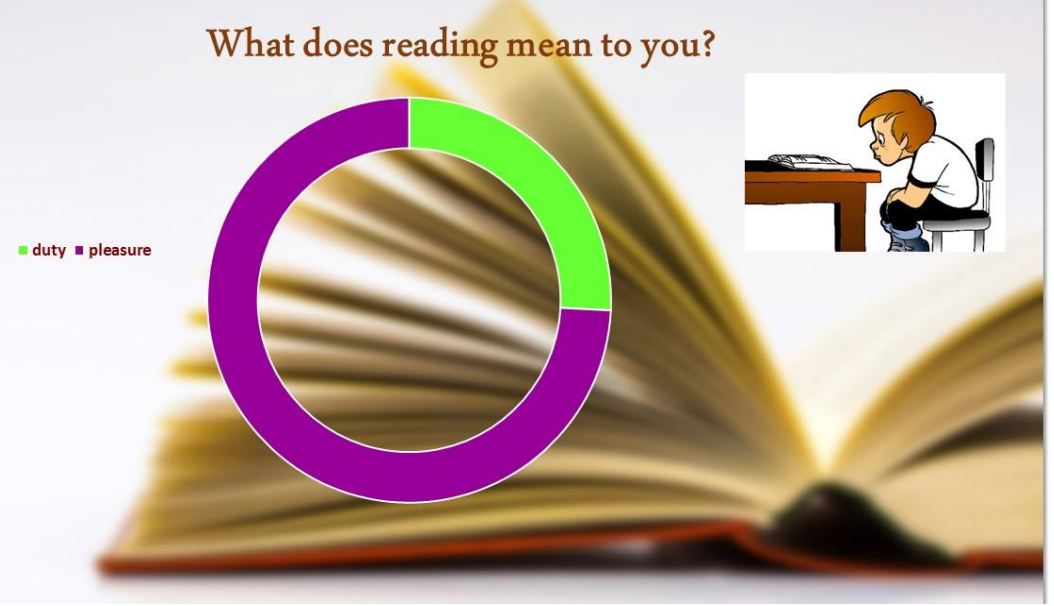

Fig. 3 What does reading mean to you? 
(Eryk)

In the school year 2016-2017, pupils of Primary School No. 28 were asked how they gain access to books. [ . . ] Slightly more than $85 \%$ of the respondents chose 'I borrow books from the library', nearly $80 \%$ indicated they buy books, slightly more than $60 \%$ are given books as gifts, slightly more than $30 \%$ borrow books from friends, and ca. $25 \%$ rely on their home libraries. It seems that more than a half of the respondents get books as gifts and most likely read them afterwards. This result surprised me as it shows that books are actually very popular gifts. The large number pupils that buy books may mean that they do not like reading used or damaged books [... ]. I have to agree because books in libraries are actually very often damaged and library users have to glue the pages themselves. At the same time, the large number of pupils borrowing books from libraries means that they are satisfied with the range of the available books.

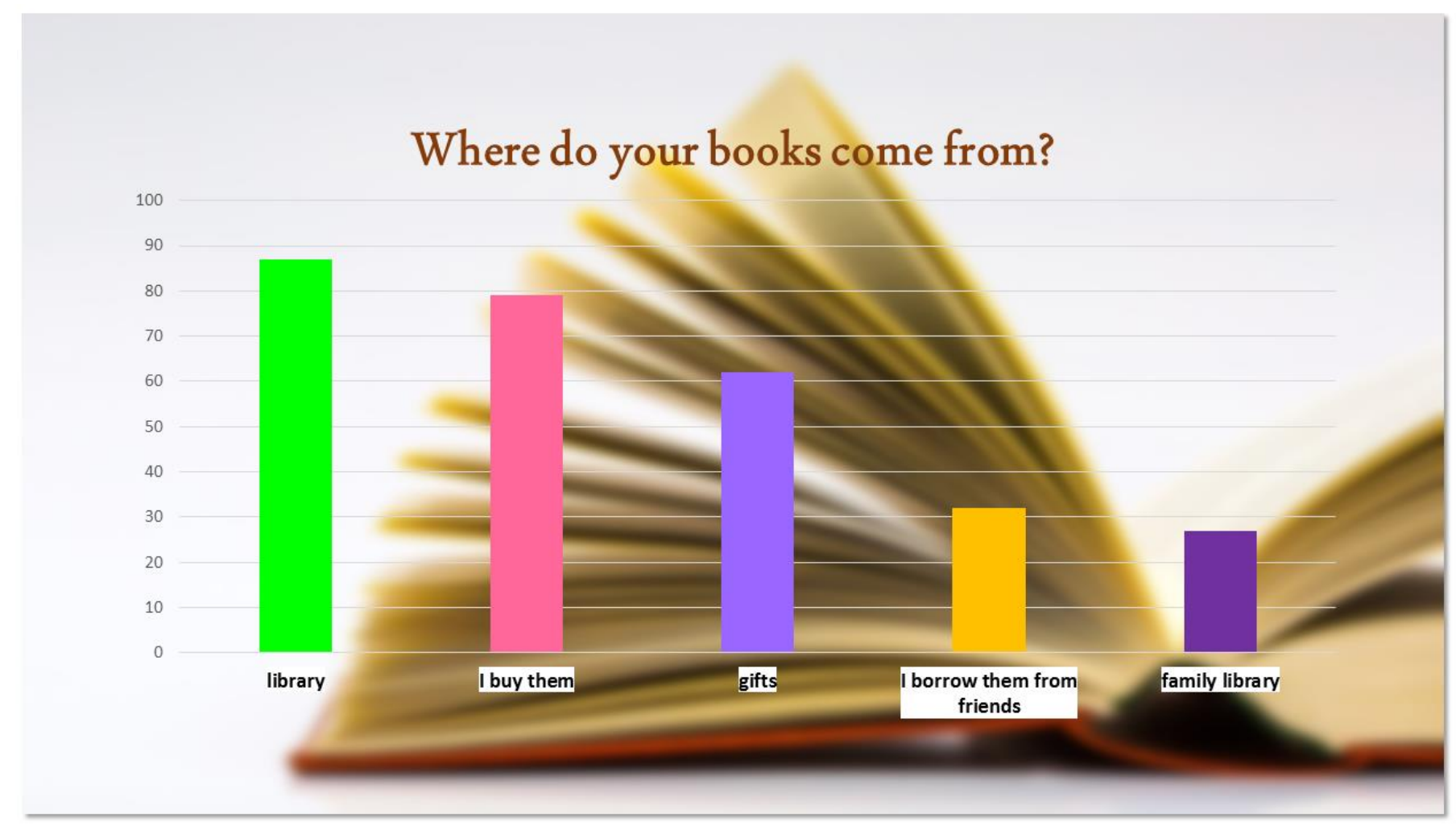

Fig. 4 Where do your books come from? 
(Dorota)

The results of the questionnaire about the offer of our school library show that 23 pupils regard the collection as rich, 65 as sufficient, and 18 as insufficient. 8 pupils answered that they do not know the collection of the school library. I was surprised because the respondents were from grades 4-6, which means they should know at least some parts of the collection. It shows that some of them have hardly ever been to the school library. I think that even if you borrow books from other libraries, it is worth knowing what is available in the school collection. I believe that if only it was possible to motivate those pupils well and encourage them to visit the school library, the whole issue would look different. Fortunately, almost all the pupils know what is available in the school collection and they can express their opinion about it: they usually find it as good. There are more and more reading promotion programs and it seems they are actually successful.

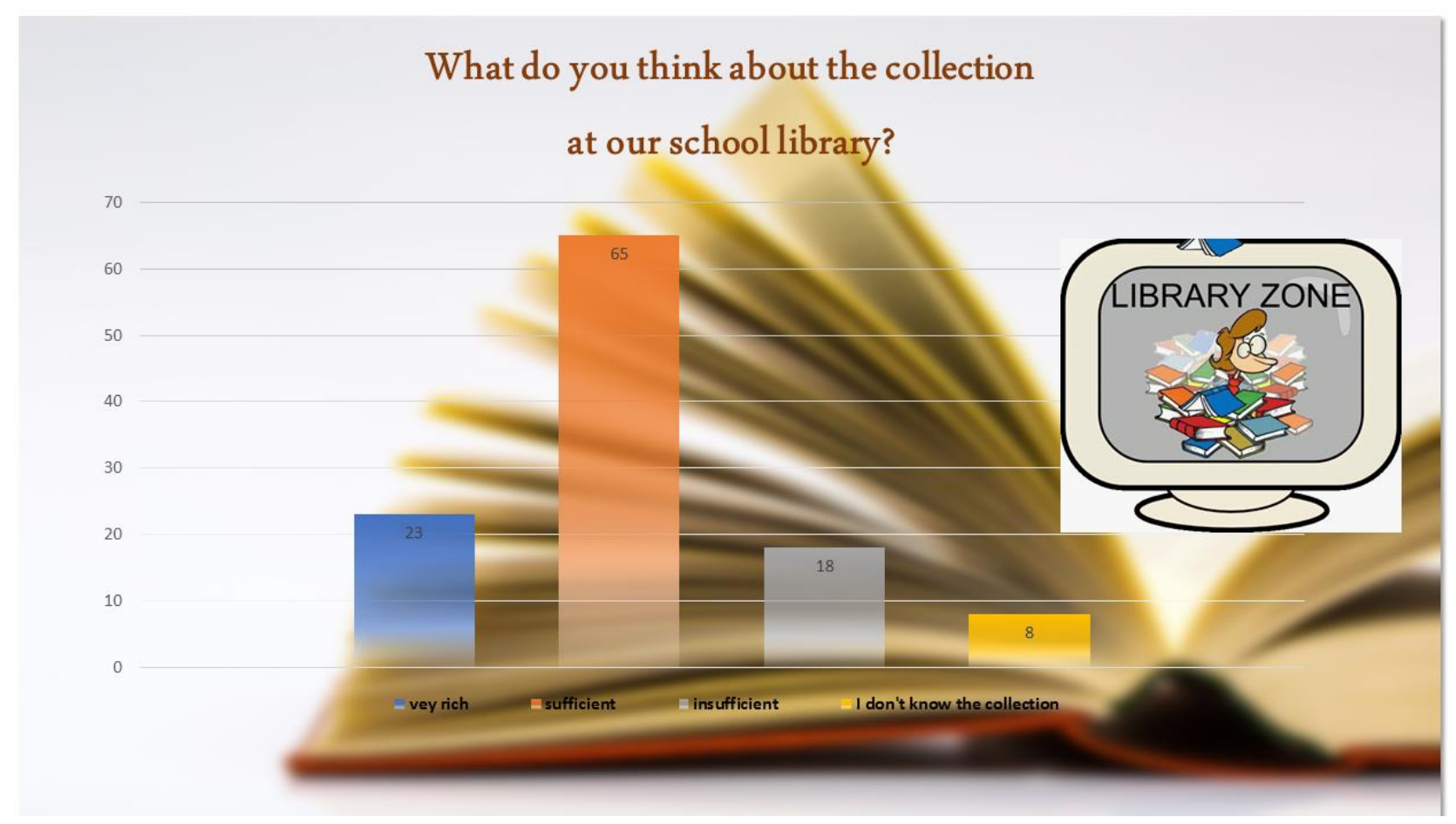

Fig. 5 Our school library 
(Milena)

I have found the substantial number of people who have encouraged us to read a big success. As many as 65 pupils have been encouraged to read by their parents. Many also started to read on their own but were further supported by their teachers. We are least encouraged to read by our grandparents and friends. Maybe it would be good to change this result and encourage our friends to read more as a way to get knowledge and have a good time.

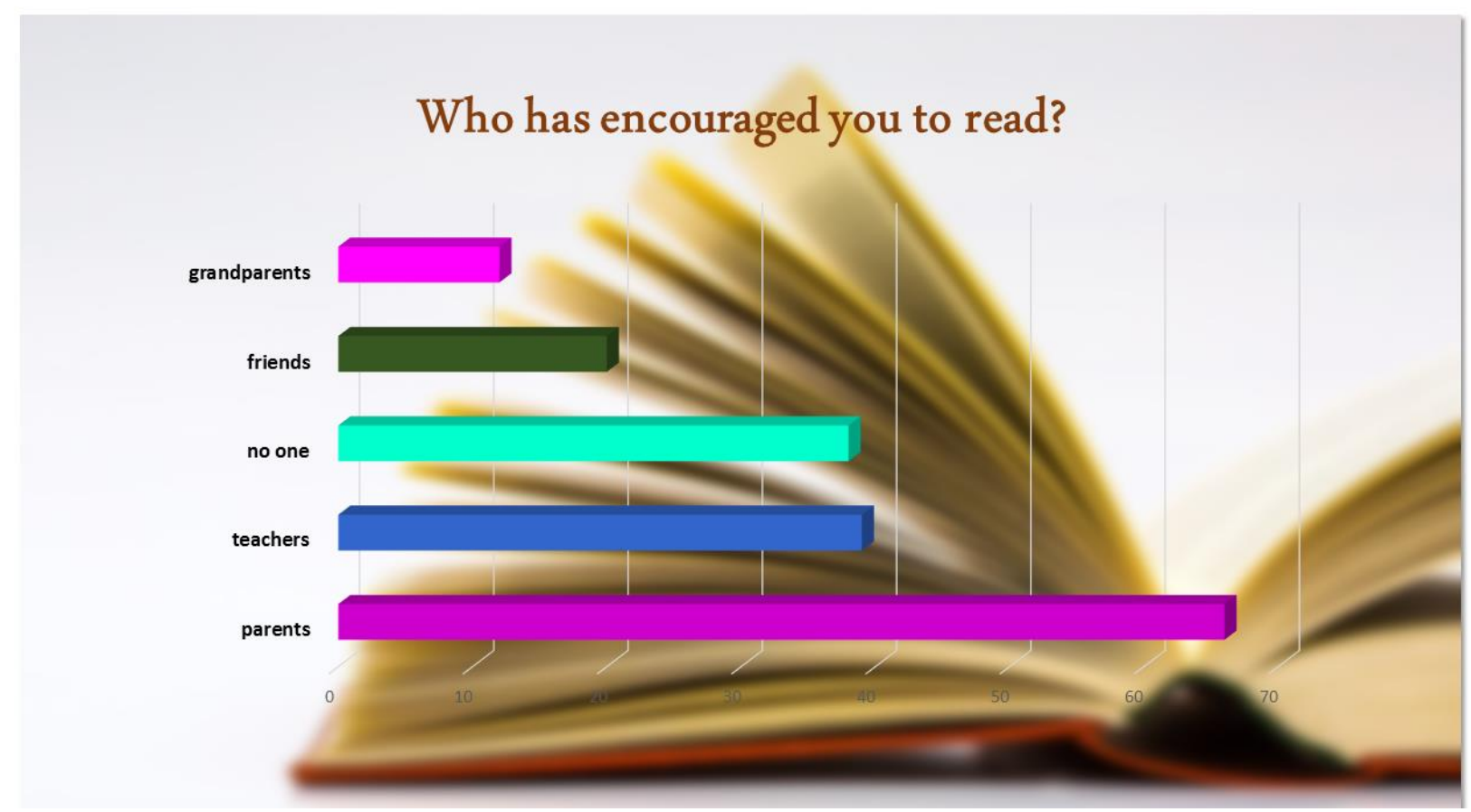

Fig. 6 Who has encouraged you to read?

\section{A Dramatic Twist with Political Overtones: Who Should Participate in Canon-Making?}

(Justyna and Mateusz)

While drawing the dissemination stage of our collaboration to a close our plans to extend the project across Poland were cut short by the reform of the educational system coming into force in autumn 2017. As part of this reform, the Ministry of National Education released a list of set texts for grades 4-8, thus leaving no room for negotiation and shared action concerning the school canon. It soon became apparent that the newly established 'adultist' 
canon, for all its attempts to introduce more generic and media diversity, fails to reflect the realities of young readers born in the digital age. It privileges the great classics of Polish literature at the expense of more up-to-date and foreign bestsellers and works of popular literature. Moreover, the list of foreign texts consists largely of old classics (e.g., Winnetou series (1893) by Karl May or A Christmas Carol (1843) by Charles Dickens) written predominantly by male authors and featuring mostly boys as protagonists. ${ }^{5}$

This stark example of centralised decision-making, with policymakers using children's and YA literature in service of a nationalist agenda, clearly stood at odds with the values on which our project was premised. We realised the ethical challenge the whole team had to face in light of the political implications of the project. Concluding that the instrumental treatment of children's literature we were witnessing was in fact a test of our approach to children as citizens, in March 2017 we co-organised and moderated a debate about the canon of primary school books in Poland. Dorota and Eryk, who by virtue of their expertise and outstanding oratory skills had been asked to speak on behalf on their peers, readily agreed to participate in the debate. They also obtained their parents' permission to do so. The other panellists were Ewa and two members of academia. The participants were asked to reflect on two principal questions: (1) Who participates and should participate in shaping the school canon in Poland? (2) What is missing from the recently revisited reading curriculum? Dorota and Eryk participated fully in the exchange and played a key role in coming up with a joint child-adult solution.

Following the debate, suggestions have been made to rectify the prevalent model of canon-making by leaving the decision for designing reading lists to organised communities of teachers, students and parents. It has also been proposed that the existing canon of books should be supplemented with graphic novels and picturebooks, with texts that are closely related to the history and culture of a given region, and with books that would more fully 
reflect the cultural, religious and sexual diversity of Polish society. Such a decentralised dialogue, based on informed decision-making and compromise, could in turn result in drawing up a consensual list of school readings that would satisfy the demand for the school canon and be a source of opportunities for exercising civic literacy and active citizenship on the part of both children and adults inside and outside the classroom.

\section{Developing an Intergenerational Dialogue}

(Justyna and Mateusz)

We hope our participatory research project paves the way for more such child-adult encounters. By situating 'children's participation within a framework of intergenerational dialogue' and by stressing 'the interdependency between children's "voice" and their sociocultural environments' (Horgan 247), it vests more power in young researchers who, as coproducers of knowledge, are given the opportunity both to shape their childhoods and to guide their adult collaborators' enquiry into children's literature. This sense of empowerment, achievement and confidence emanates from the participants' reflections on their engagement in the project.

(Dorota, Eryk, Kasia, Milena, Olga)

We have recorded short videos to evaluate the potential of intergenerational collaboration. Below are excerpts from our commentaries:

(Eryk)

The most important thing is democracy and asking students about their opinions. Children should have an influence on choosing school books. In my opinion, participation in the project was a chance for me to reflect on the Polish education system. Children's participation was especially important. I'm glad that I could help and share my opinion. [... ] Such studies join generations together and teach us how to cooperate with people different from you. They 
also encourage children to read books for fun. The project also taught the adults how to be empathic towards children.

(Dorota)

Thanks to our project, I've learnt a lot. Until now, I didn't know that more than $60 \%$ of people in Poland don't read books at all. Fortunately, in my school more than $50 \%$ of students read a lot of fantasy books and adventure books. I know that if school readings interest students, they read more. Thanks to this project, I know that if a set of school books is interesting for readers, the number of readers in society can go up. [. . .] All people involved in this project could add something to this topic. I'm happy because adults were working together with teenagers. Thanks to this, our opinions could be expressed and heard.

(Olga)

Despite the age gap, we were able to form a team based on understanding and trust.

(Kasia)

As a result of the study, we know what changes to make. We can organise events. Recently, for example, our school has held a special reading event. Both teachers and students were reading books during lessons. Taking part in the project taught us a lot: we know how to increase the number of readers, and we know that thanks to our activities there are more people who read....Working with the adults was nicer than I expected because they had interests similar to ours and we felt like we were cooperating with children at our age.

(Milena)

I had always thought that children prefer playing computer games, writing on Facebook or watching films. It surprised me that many of them actually read books in their free time. . . This project was very important to me. . . Cooperation with the adults was helpful. (Justyna and Mateusz) 
What connects all these accounts is a firm belief in the transformative and emancipatory power of intergenerational partnerships. The young researchers' close collaboration with adults proved to be a revealing experience for them, enabling them to confront and ally with the (adult) Other alongside gaining a more illuminating insight into their own lives.

(Ewa)

I share my pupils' sentiments. The participation in this venture was a big challenge for us. Following Justyna and Mateusz's suggestion and initially relying on their support, the pupils had an opportunity to become researchers. The joint meetings resulted in the pupils' organizing and carrying out a research project on reading in their school. The pupils approached the project with commitment, creativity and conscientiousness. They also carefully analyzed and interpreted the results of their inquiries. Thanks to the project, we got a better understanding of reading practices among the children (10-13 years old) attending the school, which in turn enabled us to evaluate the effectiveness of reading promotion activities organised here and plan new initiatives. Both the research process itself and the dissemination activities have been a source of great satisfaction to my pupils. I see the inclusion of pupil as partners in research as very inspirational for both parties. [. . .] Thanks to new technologies, there were no logistical problems although all the participants also had other engagements and obligations. $[\ldots]$

\section{Conclusion}

(All)

Summarising the evolution of canonicity in Poland, Przemysław Czapliński states that debates about the literary canon are in fact closely related to the issue of solidarity, that is, to the establishment of rules determining the participation in the life of a given community and to attempts to influence others (81). As he concludes, if we see the canon through the lens of solidarity, it will turn out that we are all involved in its formation (81). Our project has indeed 
proved that the canon wars may inspire collective efforts to shape the canon, including its pedagogic and institutional aspects. 'Deconstructing the Canon with Elementary School Students: Participatory Research in Practice' offers a model of a glocal approach enabling the inclusion of children into processes shaping national literary cultures.

The polyphonic organisation of this essay is certainly not the only possible way of structuring spaces accommodating intergenerational academic dialogue. ${ }^{6}$ Yet it has enabled us to show the dynamic development of our venture, the diverse ways in which we have all contributed to its realisation, and the effect it had on all of us as readers, researchers and citizens. In broader terms, our project sets a precedent for a paradigmatic change in the field of children's literature studies: it re-shifts scholarly attention to young readers as subjects producing knowledge that not only guides adult researchers in their explorations of children's books but is also acknowledged as valuable in its own right. Without reconceiving children's literature scholarship as promoting intergenerational dialogue, we risk missing on productive opportunities to work with children for the benefit of all generations.

\section{Acknowledgements}

Justyna's contribution to the article was possible thanks to funding from the European Union's Horizon 2020 research and innovation programme under the Marie SklodowskaCurie grant agreement no. 745888. We also thank Eugene Giddens for his feedback on an earlier draft of this article.

\section{Works Cited}

Alderson, Priscilla. 'Children as Researchers: Participation Rights and Research Methods. ' Research with Children: Perspectives and Practices (2nd edition). Eds Pia Christensen and Allison James. London: 2008, Routledge. 276-290. 
Czernow, Anna and Dorota Michułka. 'Historical Twists and Turns in the Polish Canon of Children's Literature'. Canon Constitution and Canon Change in Children's Literature. Eds Bettina Kümmerling-Meibauer and Anja Müller. New York and London: Routledge, 2017. 85-102.

Czapliński, Przemysław. 'Kanon i wolność. Życie literackie w Polsce po roku 1989.' Europejski kanon literacki. Dylematy XXI wieku. Ed Elżbieta Wichrowska. Warszawa: Wydawnictwa Uniwersytetu Warszawskiego, 2012. 69-81.

Gallacher, Lesley Anne and Michael Gallagher. 'Methodological Immaturity in Childhood Research?: Thinking Through "Participatory Methods"' Childhood 15.4 (2008): 49951.

Gubar, Marah. 'The Hermeneutics of Recuperation: What a Kinship-Model Approach to Children's Agency Could Do for Children's Literature and Childhood Studies.' Jeunesse: Young People, Texts, Cultures 8.1 (2016): 291-310.

Horgan, Deirdre. 'Child Participatory Research Methods: Attempts to Go "Deeper”.' Childhood 24.2 (2017): 245-259.

Hunt, Peter. 'Childist Criticism: The Subculture of the Child, the Book and the Critic.' Signal 43 (1984): 42-59.

Hunt, Peter. 'Prelude: The Case of Canons and Classics: The Impossibility of Definitions?' Canon Constitution and Canon Change in Children's Literature. Eds Bettina Kümmerling-Meibauer and Anja Müller. New York and London: Routledge, 2017. $15-19$.

James, Allison and Alan Prout. Constructing and Reconstructing Childhood: New Directions in the Sociological Study of Childhood. Oxford: Routledge, 1990. 
Kesby, Mike. 'Spatialising Participatory Approaches: The Contribution of Geography to a Mature Debate.' Environment and Planning A 39.12 (2007): 2813-2831.

Kümmerling-Meibauer, Bettina and Anja Müller (eds). 'Introduction: Canon Studies and Children's Literature'. Canon Constitution and Canon Change in Children's Literature. New York and London: Routledge, 2017. 1-14.

Lee, Nick. Childhood and Biopolitics: Climate Change, Life Processes and Human Futures. Basingstoke: Palgrave, 2013.

Moules, Tina and Niamh O’Brien. 'Participation in Perspective: Reflections from Research Projects.' Nurse Researcher 19.2 (2011): 17-22.

Richards, Sarah, Jessica Clark and Allison Boggis. Ethical Research with Children: Untold Narratives and Taboos. Basingstoke: Palgrave, 2015.

Tisdall, Kay and Samantha Punch. “ "Not So New”?: Looking Critically at Childhood Studies'. Children's Geographies 10.3 (2012): 249-264.

Wall, John. 'Childism: The Challenge of Childhood to Ethics and the Humanities.' The Children's Table: Childhood Studies and the Humanities. Ed. Anne Mae Duane. Athens, GA: University of Georgia Press, 2013. 68-84.

Warming, Hanne. ‘Getting under Their Skins? Accessing Young Children’s Perspectives through Ethnographic Fieldwork'. Childhood 18 (1): 39-53.

\footnotetext{
${ }^{1}$ See our discussion of this issue in Justyna Deszcz-Tryhubczak and Mateusz Marecki's 'Whose Canon? The Absence of Children's Voices in the Polish Canon Battle.' Journal of the History of Childhood and Youth 11.1 (2018): 81-87.
} 
${ }^{2}$ See Michelle Superle's 'The United Nations Convention on the Rights of the Child: At the Core of a Child-Centered Critical Approach to Children's Literature.' The Lion and the Unicorn 20.2 (2016): 144-162 and Justyna Deszcz-Tryhubczak's 'Literary Criticism for Children's Rights: Towards a Participatory Research Model of Children's Literature Studies' The Lion and the Unicorn 20.2 (2016): 214-231.

${ }^{3}$ Participatory research allows for the employment of diverse methods, including creative visual methods and storytelling, which in turn makes it accessible to younger children than the child researchers we have worked with. The approach we propose has to take into account particular materialities of children's life-worlds.

4 'Reading for purpose' as a selection criterion for canon-making was our starting point to grip the child researchers' attention and spur them into action. The focus of our meeting discussions quickly shifted from 'reading for purpose' to 'reading for pleasure', which demonstrates the need to include young readers in the decision-making process.

${ }^{8}$ Ewa, Justyna, Mateusz and a group of primary school pupils (11-14 years old) are currently collaborating on a participatory project "Staś and Nel in the 21st Century": Do Longestablished School Readings Connect Generations?", aimed at examining how selected texts from the school canon catalyze memories of childhood from older readers that can be shared with younger readers to produce common reading histories. The project engages children and adults as co-creators of particular memory-work methods.

Ewa Chawar, MA, teaches Polish literature and language at the Primary School No. 28 in Wrocław, Poland. She has been a voracious reader since childhood. She enjoys her job, singing and knitting. 
Dr. Justyna Deszcz-Tryhubczak is Associate Professor of Literature and Director of the Center for Young People's Literature and Culture at the Institute of English Studies, University of Wroclaw, Poland. She is the author of Yes to Solidarity, No to Oppression: Radical Fantasy Fiction and Its Young Readers (2016). Her research focuses on speculative fiction, utopianism, and child-led approaches.

Katarzyna Kowalska attends the Primary School No. 28 in Wrocław, Poland. Biographies and fantasy novels are her favourite genres, but sometimes she also gives herself up to the pleasure of reading horror stories. She likes cooking, skiing and writing stories. She is interested in molecular gastronomy and medicine. Her future goal is to become a vascular surgeon.

Olga Maniakowska, 15, attends the Ursuline Junior High School in Wrocław, Poland. She enjoys reading crime stories and fantasy novels. She likes to watch her favourite TV shows, hang out with friends or just chill out to the sounds of her favourite songs. She's interested in Japanese culture. Her goal in life is to become a lawyer

Mateusz Marecki, MA, is a foreign teacher of English in China. He's published 20 articles, reviews and academic translations, and has co-edited a book on war and words. He's been actively involved in organising and running a number of workshops and outreach projects for young readers.

Milena Palczyńska is a seventh grader at the Primary School No. 28 in Wrocław, Poland. She is interested in marital sports, animals and anime. In her free time, she immerses herself in fantasy books, goes to the swimming pool or just busies herself with creative writing. One of her dreams is to work in a big company after graduating from the University of Science and 
Technology in Wrocław, Poland. In November 2017, she co-published a collection of short stories under the title My Place.

Eryk Pszczołowski is a seventh grader at the Primary School No. 28 in Wrocław, Poland. He is an avid reader of dark fantasy novels, crime stories and popular science books. He likes to draw, read and do sports. In the future, he'd like to pursue a career in science.

Dorota Sikora is in her second year of junior high school. Since her early years she has loved reading books. She also likes reciting and takes part in a youth theatre. She enjoys helping people and animals. She plans to become a volunteer in one of the developing countries after she graduates. 